\title{
Assessing the generational impact of COVID-19 using National Transfer Accounts (NTAs)
}

\author{
Miguel Sánchez-Romero ${ }^{1, *}$
}

\section{Abstract}

An important aspect of the current COVID-19 crisis is that not all age groups are equally affected by the pandemic. To account for the generational impact of COVID19, a dynamic overlapping generations model with realistic demography, human capital and NTAs is constructed. The COVID-19 crisis is modelled through two unexpected and temporary negative shocks: an economic shock that reduces labour income, and a demographic shock that increases the mortality hazard rates of those infected. The model is applied to 12 countries for which full NTA data are available. Results are presented for two extreme fiscal policies: one in which governments compensate workers for $0 \%$ (without fiscal support) of their total labour income losses due to the pandemic, and another in which governments compensate workers for $100 \%$ (with fiscal support) of these losses. In addition, I analyse the impact of these policies on public debt. The results show that COVID-19 is affecting the financial situations of people aged 25 to 64 and their children more than those of older people. By compensating workers for their income losses, the economic impact of COVID-19 has been more evenly distributed across cohorts, reducing the burden on people aged zero to 64, and increasing the burden on people aged 65 and older. Moreover, the simulation results show that a $1 \%$ decline in labour income leads to an average increase in the debt-to-total labour income ratio of between $1.2 \%$ (without fiscal policy) and $1.6 \%$ (with fiscal policy).

Keywords: COVID-19; National Transfer Accounts; overlapping generations; lifecycle model, generational accounts; debt

\footnotetext{
${ }^{1}$ Vienna Institute of Demography (OeAW), Wittgenstein Centre of Demography and Global Human Capital (IIASA, OeAW, University of Vienna), Vienna, Austria and International Institute for Applied Systems Analysis, Laxenburg, Austria

*Correspondence to: Miguel Sánchez-Romero, miguel.sanchez@oeaw.ac.at
} 


\section{Introduction}

The COVID-19 pandemic has affected all aspects of economic and social life. From a demographic perspective, the COVID-19 pandemic has caused many deaths, an increase in morbidity among those infected, the postponement of many planned migration flows and an unequal fertility response based on socioeconomic conditions (Aassve et al., 2020). ${ }^{1}$ From an economic perspective, the COVID-19 pandemic has caused disruptions to both the supply and the demand side. On the supply side, the evolution of the pandemic has reduced the labour supply and caused disruptions in the supply of goods and services. On the demand side, the loss of income and the worsening of economic prospects, which have been more pronounced during lockdowns, have reduced household consumption.

Most economic models developed during the COVID-19 pandemic combine susceptible-infected-recovered (SIR) models with computable general equilibrium models. These models are well-suited for analysing the economic and epidemiological consequences of different policies, as well as the impact of these policies on the behaviour of agents (e.g. Eichenbaum et al., 2020; Krueger et al., 2020). One common feature of these models is that they assume that all generations are equally affected by COVID-19. Some exceptions are Brotherhood et al. (2020) and Glover et al. (2020), which analysed the impact of the pandemic on two generations (see a summary of this literature in Bloom et al. (2020) and Brodeur et al. (2021)). However, the COVID-19 pandemic has affected each generation differently. While elderly people have faced a higher probability of dying in case of a COVID-19 infection, their income has been protected through public transfers via pension systems. By contrast, workers with children and young workers have borne the economic consequences of lockdowns, either through reductions in the effective time worked, or through income losses. To mitigate the negative effects of this crisis and of other future pandemics, which hit some generations harder than others, the generational economy should be investigated. To complement the recent literature on this topic, models should be developed that use economic information by age, and by the extent to which different age groups are supported through familial and public transfers, such as the information provided by the National Transfer Accounts (NTA) project, to assess the impact of the COVID-19 crisis on the generational economy.

In this article, we develop an overlapping generations (OLG) model that uses data from the NTA project. The NTA project (https://ntaccounts.org) provides crosssectional age profiles that are fully consistent with National Accounts (Lee and Mason, 2011). NTAs are theoretically founded on the OLG models developed by Samuelson (1958), Tobin (1967), Arthur and McNicoll (1978), Willis (1988), Lee (1994) and Bommier and Lee (2003), among many others. An OLG model is characterised by a population composed of several agents who are born in

\footnotetext{
Research on the impact of the COVID-19 pandemic on fertility can be conducted using the ShortTerm Fertility Fluctuations from the Human Fertility Database (https://www.humanfertility.org).
} 
different years and have a finite length of life. Consequently, the model allows agents from different generations to overlap, which enables the analysis of the economic consequences of the interaction of agents with different ages, while controlling for compositional changes of the population (i.e. changes in the age structure and in the composition of each age over time). Thus, although the main goal of the NTA project is to improve our understanding of the impact of changes in the population age structure on national economies, by combining the NTAs with an OLG model, many other questions can be studied in a dynamic framework. For instance, NTAs can be used in OLG models to examine the impact of the COVID-19 pandemic on the generational economy in the short and the long run.

As well as drawing on NTA data (2019), the OLG-NTA model combines realistic demographic data from the UN Population Division (2019), and human capital data from the WIC Human Capital Data Explorer (2018). The model includes an unexpected economic shock and an unexpected demographic shock. The economic shock due to the lockdown measures is assumed to have a direct negative impact on labour income, and an indirect negative effect on consumption, on public transfers (i.e. reducing fiscal revenues) and on private transfers (i.e. reducing transfers from parents to children). Following Sánchez-Romero et al. (2021), the demographic shock is modelled using the fraction of people infected with COVID-19 during 2020. The demographic shock is assumed to increase the death rate of people who are infected in 2020, and to leave around $10 \%$ of individuals who are infected and survive with long-term health conditions, which permanently increases the death rate (Marshall, 2020). ${ }^{2}$ See the details in Appendix A.1. Hence, the demographic shock has a direct negative effect on public health care transfers due to both the additional expenses associated with providing care for people infected with COVID19 , and the reduction in the stock of human capital as a result of the person-years lost. The demographic shock also has indirect effects on consumption, private transfers and public transfers because of the changes in life expectancy and in the age distribution of the population.

The OLG-NTA model is applied to 12 countries for which NTA data are available (Australia, Austria, Brazil, Colombia, Costa Rica, Finland, Hungary, Italy, Japan, Slovenia, Sweden and the US). For the sake of comparability across countries, we use the same parameter values in all countries. The parameters were calibrated to Austrian NTA profiles in the year 2010. The estimated negative impact of the COVID-19 pandemic on labour income across the selected NTA countries ranges from $-5.6 \%$ in Australia to $-16 \%$ in Italy, with an average decrease of $-10.2 \%$.

\footnotetext{
2 This number may represent the lower bound of the proportion of people left with long-term health conditions after being infected with COVID-19. Given that the fraction of people infected who required hospitalisation was around $20 \%$ of the total cases detected, and that $70-80 \%$ of these individuals may have developed long-term health conditions (Lopez-Leon et al., 2021), it is likely that the fraction of people with long-term health conditions due to COVIDs-19 is slightly higher than $10 \%$. However, these numbers should still be interpreted with caution, since the likelihood of experiencing long-term health conditions might not be associated with the severity of the disease (Townsend et al., 2021).
} 
To reflect the difficult trade-offs governments face during the pandemic, two extreme policy options are analysed. In the first option, governments do not compensate workers for their labour income losses caused by the restrictions imposed to control the spread of the pandemic. This option will lead to a higher unemployment rate that will complicate the recovery of the economy. This option is introduced by assuming that half of the labour income losses from 2020 will persist in 2021, and that a quarter of the labour income losses from 2020 will persist in 2022. In the second option, governments fully compensate workers for their labour income losses due to the pandemic restrictions. While this policy option will improve the chances of an economic recovery and offset workers' pandemic-related labour income losses in 2021 and 2022, it will raise public debt levels and increase the burden on future taxpayers. These two extreme policies provide information on the minimum and maximum impact that a pandemic such as COVID-19 may have on fiscal revenues and on public debt. The main results of the OLG-NTA model on aggregate consumption, public debt and tax revenues are as follows:

- All age groups experience a decrease in consumption in 2020 due to the COVID-19 pandemic. However, the decline in consumption is greater for the 25-64 age group than for other age groups.

- A $1 \%$ decrease in labour income leads to an average increase in the debt-tototal labour income ratio of between $1.2 \%$ (without fiscal support) and $1.6 \%$ (with fiscal support).

- Assuming that the debt-to-GDP ratio is reduced by $10 \%$ per year from 2022 onwards, a $1 \%$ decrease in labour income leads to an average increase in the total tax revenue during the 2020 s of $0.074 \%$ if the government does not compensate workers for their labour income losses, and of $0.104 \%$ if the government fully compensates workers for their labour income losses.

The economic and demographic consequences of the current pandemic will likely have effects not only over the short term, but over the medium term as well. Therefore, to analyse the impact of COVID-19 on each generation, it is necessary to take a lifecycle perspective. To do so, we have used two longitudinal measures: lifetime consumption and lifetime transfers. Lifetime consumption may be defined as the present value, survival weighted, of the remaining consumption until death; while lifetime transfers may be defined as the present value, survival weighted, of the remaining total net transfers (i.e. public and private net transfers) until death. These two measures take into account both the economic shock and the demographic shock. The main results of our analysis on the impact of a pandemic such as COVID-19 on the generational economy are as follows:

- Without fiscal support, a $1 \%$ decrease in labour income leads to an average decline in lifetime consumption of $0.73 \%$ for the $0-24$ age group, of $0.94 \%$ for the 25-64 age group, and of $0.32 \%$ for the $65+$ age group. However, when governments fully compensate households for their labour income losses, a $1 \%$ decrease in labour income leads to an average decline in lifetime consumption of $0.24 \%$ for the $0-24$ age group, of $0.46 \%$ for the $25-64$ age 
group, and of $0.40 \%$ for the $65+$ age group. Therefore, when workers are compensated for their losses, the economic impact of COVID-19 is more evenly distributed across cohorts, significantly reducing the burden on people aged 0-24 and 25-64, and increasing the burden on people aged 65+.

- The impact of the COVID-19 pandemic on lifetime consumption is mainly explained by the changes in lifetime transfers, which shows that NTAs can be used to account for both public and private transfers.

- Compensating workers for their labour income losses has a positive effect on total lifetime transfers for the 0-24 age group. Indeed, a 1\% decline in labour income leads to an average decline in total lifetime transfers of $0.61 \%$ without the additional support from the government, and of only of $0.29 \%$ with the additional support from the government.

- The positive effect of the additional fiscal support on the lifetime transfers of children is due to an indirect positive effect on private lifetime transfers, and not to an increase in public lifetime transfers. Without fiscal support, parents reduce their transfers to their children in response to the decline in their labour income. However, when the government compensates parents for their labour income losses, the level of transfers from parents to their children does not change.

- The impact of the COVID-19 pandemic on public lifetime transfers for the $65+$ age group is ambiguous without the additional government support and is negative when the government compensates workers for their labour income losses.

This article is organised as follows. In Section 2, we list the NTA profiles used for constructing an NTA-based model with a dynamic overlapping generations model (hereafter, the OLG-NTA model), and its necessary adjustments. In Section 3, we show how the NTA profiles may have been affected by the COVID-19 pandemic in 2020. In Section 4, we analyse the impact the COVID-19 pandemic has had on labour income, debt and taxes. In Section 5, we analyse the impact of the COVID-19 pandemic on consumption, private transfers and public transfers for the generations alive in 2020. All of the results presented in Sections 4 and 5 are based on two extreme scenarios that reflect the minimum and the maximum increase in debt caused by the COVID-19 pandemic. In the final section, we discuss the main assumptions, limitations and potential extensions of the OLG-NTA model. The article also has an Appendix in which we explain the formulas needed to construct the OLG-NTA model, and that allow for the replication of this analysis in other countries with current NTA data.

\section{Constructing an OLG-NTA model}

To better represent the microeconomic behaviour of households of different ages, rather than to just account for compositional changes, the OLG-NTA model uses a selected set of NTA profiles. In addition, to make the NTA profiles consistent with 
a simplified version of an OLG model, we need to introduce several assumptions, which are listed in Box 1.

\section{Box 1. Assumptions}

The following assumptions are borrowed from the OLG literature in order to make the NTA profiles consistent with the OLG-NTA model implemented here: credit markets are perfect, individuals have perfect foresight, there is no bequest motive, individuals fully annuitize their wealth and public and private transfers are non-distortionary. The interest rate is determined in international capital markets, and the wage rate per hour worked increases at a constant rate. In addition, we assume that agents take the number of hours worked in the market as given, and only make decisions about the consumption of the household. Households are comprised of a household head and a number of dependent children. Hence, household heads take the revenues from the market and optimise consumption for all household members. Over the lifecycle of each household head, the number of dependent children varies because of fertility, mortality and children leaving their parents' home. For simplicity, we also assume that all children leave their parents' home at the same age. In reality, children leave their parents' home at different ages, which could be captured using different home leaving rates. However, to take these differences into account, households that are settled at different ages of the household head would have to be modelled. There is one representative neoclassical firm that produces, using a Cobb-Douglas production function, a single good that can be stored or consumed. The government is assumed to run a balanced budget without the COVID-19 pandemic, and to allow the public budget to become imbalanced during the COVID-19 crisis, which raises public deficit and debt levels. Finally, it is assumed that these debts will be paid in the future through additional taxes.

Although OLG models can be computed without the stringent assumptions specified in Box 1, any deviation from these assumptions will impose theoretical restrictions on the OLG-NTA model that significantly increase its complexity. Nonetheless, these assumptions will allow us to model the standard demographic compositional effects (changes in age, size and education), as well as the behavioural effects. The next subsection specifies the NTA profiles that are used to construct the NTAbased model. The detailed derivations of each of the following profiles is given in Appendix B.

\subsection{Per capita profiles}

The OLG-NTA model is comprised of three sets of per capita profiles that differ by the degree of complexity in their construction:

i. Raw NTA profiles, 
ii. Exogenously constructed NTA profiles and

iii. Endogenously calculated NTA profiles.

The first set of NTA profiles (raw NTA profiles) are taken directly from the NTA database, and are assumed to change over time at the same rate as labour income. The exogenously constructed NTA profiles are not taken from the NTA database. Instead, a specific set of formulas are used to generate these profiles. The endogenously calculated NTA profiles are also not taken from the NTA database. Instead, these profiles are derived by solving the household problem using optimal control. Next, we list the profiles contained in each case.

i. Raw NTA profiles

All raw NTA profiles change each year at the same rate as the average labour income between ages 30 and 49. We use the average labour income between ages 30 and 49 to reduce the importance of the educational and retirement decisions in the simulation results. Table 1 shows the raw NTA profiles used in the OLG-NTA model.

ii. Exogenously constructed NTA profiles

In this category, we have four profiles: (i) labour income (YL); (ii) public transfers, health (TGH/CGH); (iii) social protection, unemployment; and (iv) inter-household

Table 1:

NTA flow accounts used

\section{Private consumption}

\begin{tabular}{|c|c|c|c|}
\hline $\begin{array}{l}\text { Education } \\
\text { Health }\end{array}$ & $\begin{array}{l}\text { CFE } \\
\text { CFH }\end{array}$ & & \\
\hline \multicolumn{4}{|l|}{ Private transfers } \\
\hline $\begin{array}{r}\text { Inter-household } \\
\text { transfers (net) }\end{array}$ & TFB & & \\
\hline \multicolumn{2}{|c|}{ Public transfers, in-kind, inflows } & \multicolumn{2}{|c|}{ Public transfers, in-kind, outflows } \\
\hline Education & TGEI/CGE & $\begin{array}{l}\text { Education } \\
\text { Health }\end{array}$ & $\begin{array}{l}\text { TGEO } \\
\text { TGHO }\end{array}$ \\
\hline Other in-kind & TGXI/CGX & Other in-kind & TGXO \\
\hline \multicolumn{2}{|c|}{ Public transfers, in-cash, inflows } & \multicolumn{2}{|c|}{ Public transfers, in-cash, outflows } \\
\hline Pensions & TGSOAI & Pensions & TGSOAO \\
\hline $\begin{array}{l}\text { Social protection other } \\
\text { than pensions }\end{array}$ & TGSI & $\begin{array}{l}\text { Social protection other } \\
\text { than pensions }\end{array}$ & TGSO \\
\hline Other cash & TGXCI & Other cash & TGXCO \\
\hline
\end{tabular}


transfers from retirees to adult children. These four profiles are derived from datasets that contain economic and demographic information that vary by cohort and over time (e.g. WIC Human Capital Data Explorer, UN Population Database). As the constructed labour income profiles are assumed to be sensitive to the level of education and experience, they differ across cohorts and countries. The public health and social protection (unemployment) transfer profiles explicitly capture the higher costs in the health care sector caused by the COVID-19 shock, and the increase in cash transfers in response to the labour income losses caused by the lockdown measures. The social protection profiles account for the government programs implemented to mitigate the income losses produced by the lockdown measures. The profiles of the interhousehold transfers from retirees to adult children capture the assistance provided by public pension recipients to their adult children.

iii. Endogenously constructed NTA profiles

A profile is endogenously constructed when it is the result of an optimisation process. Three NTA profiles are endogenously calculated in the OLG-NTA model:

- Private consumption other than health and education (CFX),

- Intra-household transfers (TFW) and

- Private asset-based reallocations (RAF).

\subsection{Aggregate profiles}

Aggregate profiles are obtained by multiplying the per capita profiles, listed in Section 2.1, by the population size at each age. The sum across ages of the aggregate profiles gives the macro totals from the National Accounts. This step is important because the aggregate totals affect the inflows and/or the outflows of public transfers, which are always constrained by public budgets. Since public budgets are affected over time by different political parties, to simplify the calculations, we assume that governments run a balanced budget in all years except for those affected by the COVID-19 pandemic. Thus, this strategy allows us to analyse the marginal effects of the pandemic on the public budget.

When the age structure of the population changes with respect to the base year of the NTA profiles, a mismatch between the inflows and outflows arises. To adjust all public NTA profiles forwards and backwards in time and to avoid this mismatch, we introduce a temporal adjustment factor that guarantees that aggregate inflows and aggregate outflows are balanced. In particular, we assume that in-cash public transfer outflows and public transfer outflows for health care are adjusted to finance all of the in-cash public transfer inflows (i.e. pensions, social benefits, unemployment, etc.), as well as health care public transfer inflows (TGHI). Since in-cash transfers and health care spending are mostly received by elderly people, this adjustment implies that the social contributions and taxes that pay for social benefits and health care will increase in the future, and were lower in the past. In contrast, given that in-kind public transfer inflows for education and other in-kind 
services are mostly received during childhood, we adjust the levels of in-kind public transfer outflows (i.e. taxes). Therefore, in-kind public transfer outflows will either decrease or remain the same relative to labour income in the future, and were higher in the past.

To isolate the economic impact of the COVID-19 pandemic, the balanced budget assumption is relaxed from 2020 onwards. We use two alternative populations: one population that is based on the UN Population Division data, which is labelled with subscript 0 ; and a second population that is affected by the COVID-19 crisis, which is labelled with subscript 1 . The construction of each population is explained in Appendix A. Given that most countries have chosen to implement expansionary fiscal policies to reduce the economic burden of the COVID-19 pandemic, the OLGNTA model assumes that the per capita public transfer inflows remain unchanged during the economic crisis caused by the COVID-19 pandemic, and that only the public transfer outflows (i.e. taxes and contributions) are adjusted downwards because of labour income losses. Consequently, governments will run deficits, and their debt levels will increase.

\section{Impact of the COVID-19 pandemic on NTA profiles}

The last step needed to finalise the OLG-NTA model is to specify the economic shock and the demographic shock. The economic shock caused by the COVID-19 pandemic is assumed to have a direct impact on public health care transfers, due to both the additional spending required to take care of people infected by the virus, and the labour income losses caused by the lockdown measures imposed by the government. The labour income losses are modelled as a decline in working hours. Government fiscal balances are also affected by the COVID-19 pandemic due to the decrease in labour income, which, in turn, leads to a decline in tax revenues and social contributions. The demographic shock is modelled using the fraction of people infected since the beginning of the pandemic, which is assumed to increase the death rate of those infected.

To represent the impact of the COVID-19 pandemic on the NTA profiles, we have chosen two countries that differ in terms of their stage of the demographic transition and their per capita income level. Figure 1 shows the impact of the COVID-19 pandemic on the NTA profiles in 2020 in Brazil (top panels) and in the US (bottom panels). Figure 1 displays in the left-hand panel the NTA-based model results for per capita labour income (red), public transfers (blue), private transfers (green) and total consumption (purple). The panel on the right-hand side shows the aggregate profiles (i.e. multiplied by the population size at each age) for labour income (red), public transfers (blue), private transfers (green) and total consumption (purple). The dashed lines represent the NTA profiles in the hypothetical case in which neither the lockdown measures nor the COVID-19 pandemic occurred. The solid lines represent the expected NTA profiles given the COVID-19 pandemic and the assumed impact of the lockdown measures on working hours. The differences 
between the two types of lines correspond to the marginal impact of the COVID-19 pandemic on each NTA profile in 2020. The increase in public transfers (TG) reflects the decrease in tax revenues and social contributions due to the labour income losses, as well as the increase in social benefits and the rise in health care spending. Private consumption declines due to the containment measures implemented to encourage social distancing (Eichenbaum et al., 2020), which leads to a reduction in total consumption. The green solid line shows that due to the decrease in consumption by parents, children receive lower private transfers, which, in turn, negatively affects their consumption as well. As a result of the decline in consumption in response to the COVID-19 pandemic, none of the age groups is better off in 2020.

The NTA profiles for the 10 remaining countries are shown in the Supplementary Material (Section S3, available at https://doi.org/10.1553/populationyearbook2022. res1.2). In addition, the list of countries for which the OLG-NTA model can be calculated is shown in Table S10 in the Supplementary Material (Section S5).

\section{Impact of the COVID-19 pandemic on labour income, debt and taxes}

The OLG-NTA model can also be used for analysing the evolution of macroeconomic aggregates (i.e. total taxes, total public and private consumption, total labour income, debt, etc.), and, hence, the macroeconomic impact of the COVID19 pandemic. To assess the aggregate economic impact of the demographic and economic shocks produced by the COVID-19 pandemic, it is necessary to compare the OLG-NTA model results with and without the shocks (c.f., solid and dashed lines in Figure 1).

In addition, we should not forget that the macroeconomic impact of the COVID19 pandemic can be exacerbated or be mitigated through public policies. However, the implementation of these policies is associated with difficult trade-offs. For instance, governments are adopting large-scale fiscal packages to support businesses and workers who have lost revenues and labour income. This policy raises public debt levels, which, in turn, increases the burdens on future taxpayers. However, a failure to financially support businesses and workers may lead to bankruptcies and unemployment, which could complicate the recovery of the economy once the pandemic is controlled. To incorporate this trade-off into the OLG-NTA model, we consider two options. If the government does not compensate workers for their labour income losses, it is assumed that half of those labour income losses from 2020 will persist in 2021, and a quarter of the labour income losses from 2020 will persist in 2022. In contrast, if the government compensates workers for their labour income losses, these fractions are assumed to be reduced by the same proportion as the fraction of labour income losses compensated by the government in 2020 . Thus, if governments compensate workers for all of their labour income losses from 2020 onwards, we assume that from 2021 onwards, the level of employment will 


\section{Figure 1:}

Simulated economic lifecycle in Brazil (top panel) and the US (bottom panel) in 2020: Pre COVID-19 (dashed lines) vs. post COVID-19 (solid lines)

National Transfer Accounts, Brazil (year 2020)
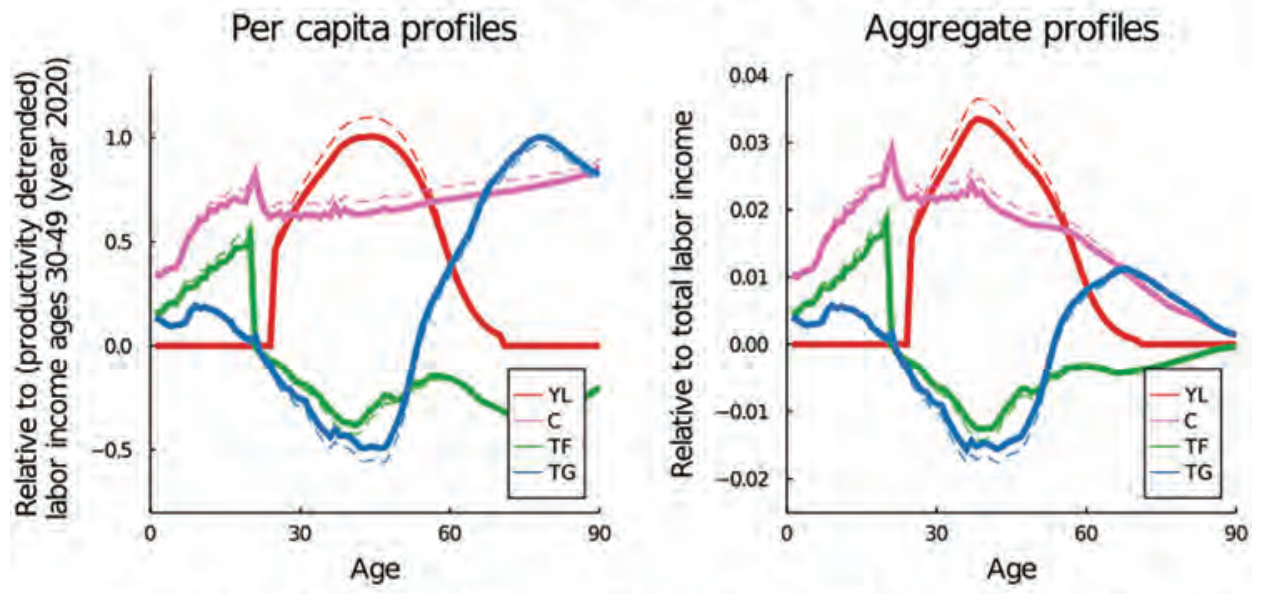

National Transfer Accounts, United States of America (year 2020)

Per capita profiles

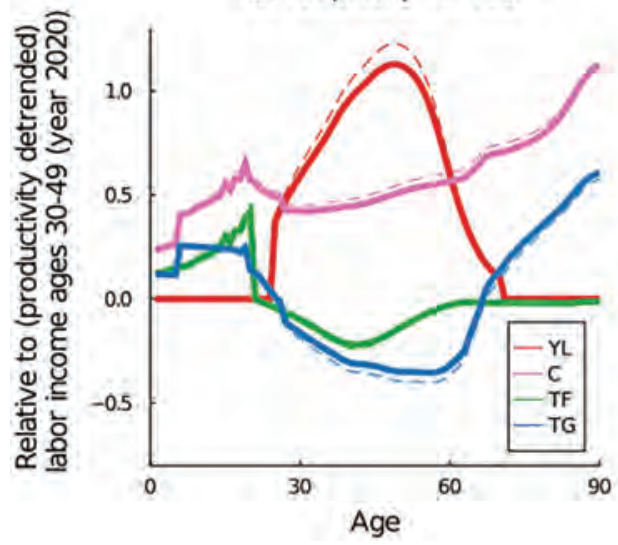

Aggregate profiles

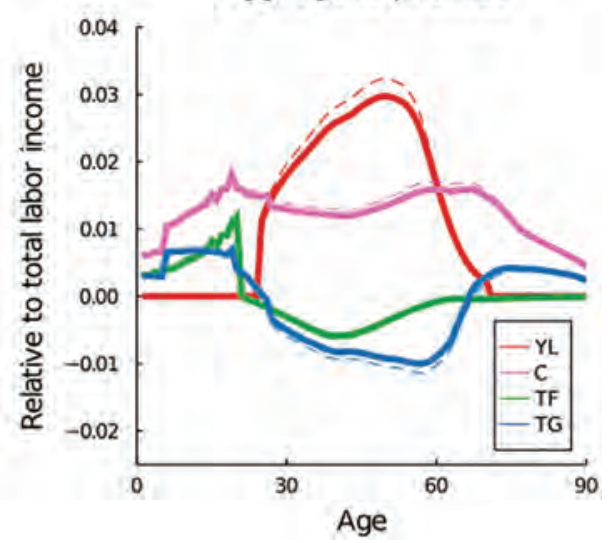

Source: Own calculations.

Notes: $\mathrm{C}$ is total consumption, YL is labour income, TF is net private transfers, and TG is net public transfers.

remain at the pre-crisis level. While not fully realistic, these two options reflect the minimum and the maximum increase in debt that a government can incur.

Not all countries have been hit equally hard by the pandemic. Figure 2 shows the estimated growth rate of the total wage bill in 2020 across the selection of 12 NTA 
Figure 2:

Growth rate of the total wage bill in $\mathbf{2 0 2 0}$ before government compensation

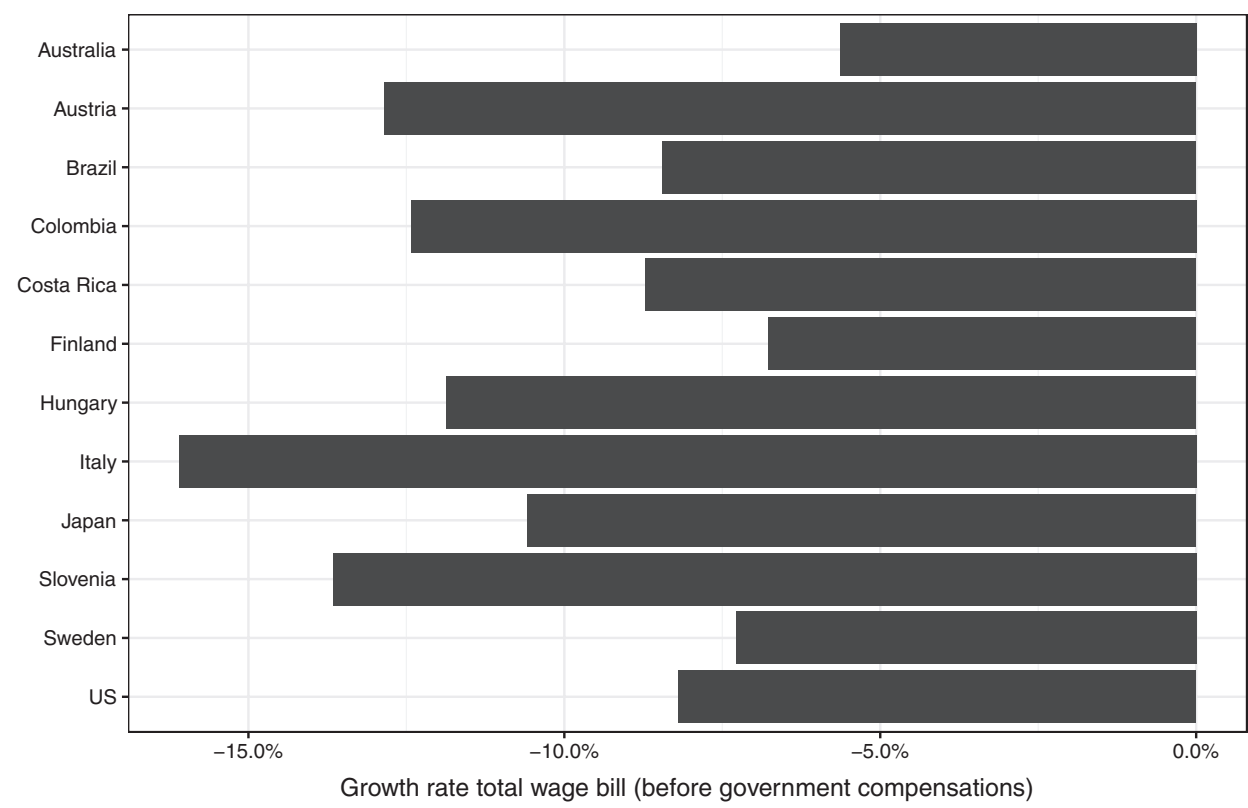

Source: Own calculations using data from Eurostat and Sánchez-Romero et al. (2021).

Note: Details of the derivation are provided in the Supplementary Material (Section S2).

countries. Figure 2 shows that the negative impact of the COVID-19 pandemic on labour income (before government fiscal support) across the selected NTA countries ranges from $-5.6 \%$ in Australia to $-16 \%$ in Italy, with an average impact of $-10.2 \%$. These numbers reflect the direct link between the fraction of people infected with COVID-19 and the decrease in economic activity. Indeed, the regression results shown in the Supplementary Material (Section S2) suggest that a $1 \%$ increase in the fraction of people infected leads to a decline of $0.25 \%$ in the annual value added.

\subsection{Impact on debt}

The cross-country differences in the impact of the COVID-19 pandemic on labour income implies that some countries will have a greater imbalance in their public coffers than others, and that this gap will be more pronounced in countries where the decline in labour income has been greater. During the crisis, tax revenues and social contributions that are generally used to finance in-cash (e.g. public benefits) and in-kind (e.g. public consumption) public transfers are reduced. Using 
the OLG-NTA model, Figure 3 shows for a selection of NTA countries the additional debt accumulated due to the pandemic. Thus, following Wyplosz (2020), we use the value of the debt in 2022, which coincides with the assumed recovery of the precrisis labour income levels. Each country has two coloured bars, which correspond to two extreme policy options that a government can implement to compensate workers for their labour income losses. The red bars show for each country the additional debt needed to support all in-cash and in-kind public transfers, given the decline in taxes and contributions collected by the government. The turquoise bars differ from the red bars in that they include the additional increase in debt caused by fully compensating workers for their labour income losses. The red bars indicate that those countries that have the largest decreases in labour income (see Figure 2) are also those that have the largest increases in debt. Thus, the additional increase in debt (relative to the total wage bill) caused by the COVID-19 pandemic across the selected NTA countries ranges from 5.6\% in Australia to $20 \%$ in Italy, with an average increase of $12 \%$. The turquoise bars show that if the government fully compensates households for their labour income losses, the additional increase in debt (relative to the total wage bill) is higher, and ranges from 8.5\% in Australia and $27.5 \%$ in Italy. Another interesting result is obtained by comparing the estimated

\section{Figure 3:}

Expected impact of the COVID-19 pandemic on debt: By level of labour income losses compensated by the government

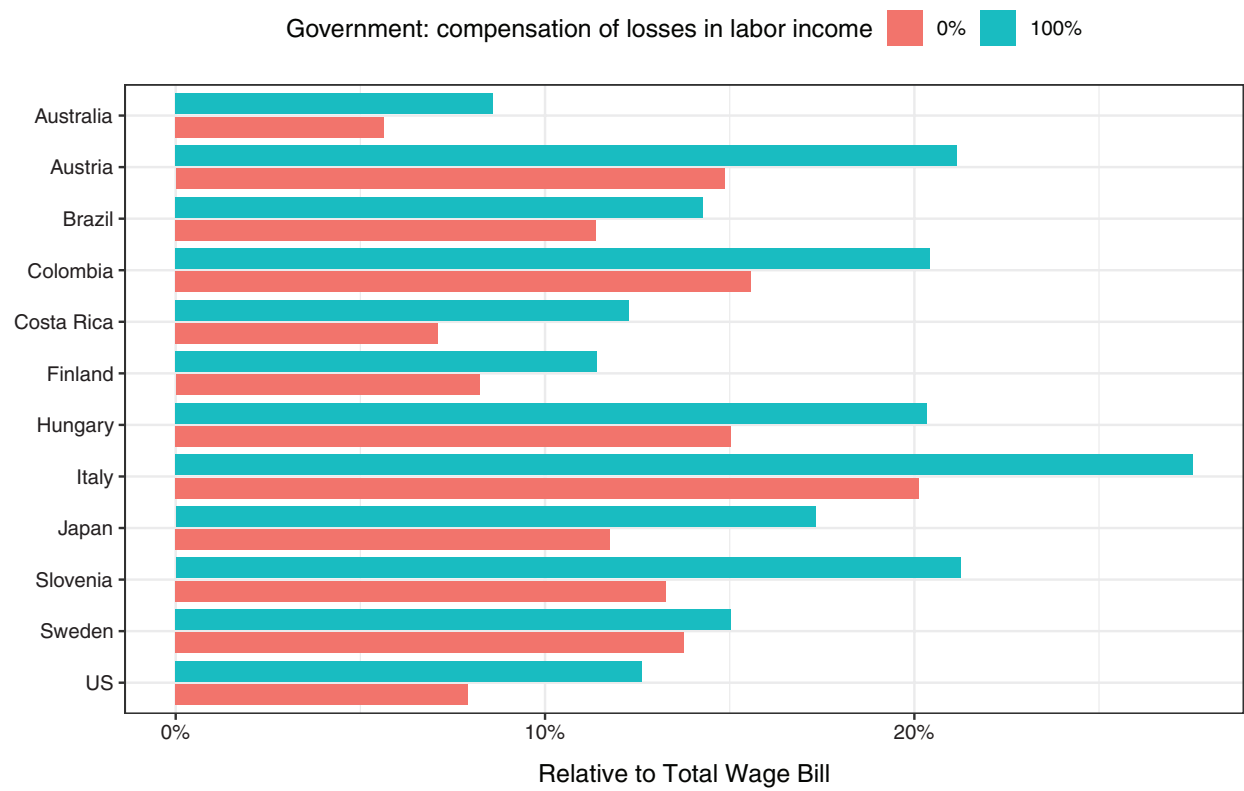

Source: Own calculations. 
impact of COVID-19 on labour income (see Figure 2) to the estimated impact of the COVID-19 pandemic on debt. This comparison suggests that if the government does not compensate workers for their labour income losses, a $1 \%$ decrease in labour income leads to an average increase in debt of $1.2 \%$ relative to the total wage bill. However, the turquoise bars suggest that if the government fully compensates workers for their labour income losses, a $1 \%$ decrease in labour income leads to an average increase in debt of $1.6 \%$ relative to the total labour income. Therefore, according to the OLG-NTA model, a $1 \%$ decline in labour income leads to an average increase in debt of between $1.2 \%$ and $1.6 \%$ relative to the total labour income.

\subsection{Impact on taxes}

The additional debt accumulated will be paid by future taxpayers. Figure 4 shows the resulting average increase in total tax revenues relative to the total wage bill during the 2020s if the debt, relative to GDP, is reduced by $10 \%$ per year. Figure 4 shows that if the government does not compensate workers for their labour income

\section{Figure 4:}

Increase in total tax revenues (relative to the total wage bill) to pay for the additional debt caused by the COVID-19 pandemic from 2021-2030: By level of labour income losses compensated by the government

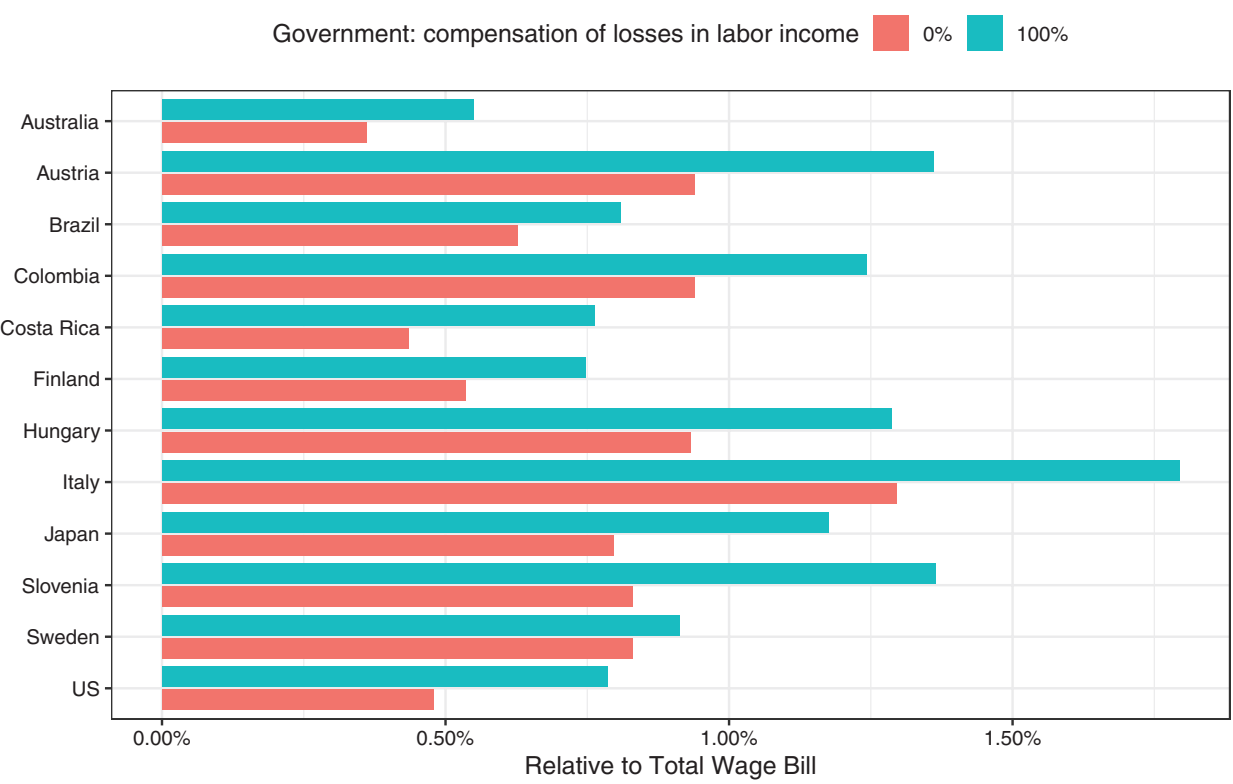

Source: Own calculations. 
losses, taxes will increase from $0.36 \%$ in Australia to $1.3 \%$ in Italy. In contrast, Figure 4 also shows that if the government compensates workers for their labour income losses, taxes will increase from $0.55 \%$ in Australia to $1.8 \%$ in Italy.

A comparison of the estimated tax increases (see Figure 4) and the estimated labour income losses (see Figure 2) across countries suggests that a 1\% decline in labour income leads to an average increase in total tax revenues of $0.074 \%$ if the government does not compensate workers for their labour income losses, and of $0.104 \%$ if the government fully compensates workers for their labour income losses.

\section{Impact of the COVID-19 pandemic on the generational economy}

To understand the impact of the COVID-19 pandemic on each generation, is necessary to know how the COVID-19 crisis will affect the evolution of the NTA profiles in the future, while taking into account that populations are not stable, and that economies do not grow at a constant rate. Fortunately, the OLG-NTA model generates NTA cross-sectional and longitudinal age profiles even when the economy is not growing at a constant rate and the population is not stable. Moreover, the NTA profiles generated by the OLG-NTA model are financially consistent because it is assumed that individuals cannot run up an ever-increasing level of debt beyond that which financial institutions would allow, or have an ever-increasing level of wealth that would minimise the consumption of the household. The latter situation may occur in models in which NTA profiles are fixed over time, and only the population age structure is allowed to change.

\subsection{Impact on consumption}

To capture the long-term effects of the current economic and demographic crises on each generation, it is necessary to use a metric with a longitudinal perspective. To do so, it is convenient to use the concept of lifetime consumption, or, equivalently, the present value of the remaining lifetime of own consumption (public and private). Lifetime consumption captures how consumption evolves over the remaining lifetime given all of the remaining resources people are expected to have (labour income, transfers and assets). Thus, calculating the change in lifetime consumption before and after the COVID-19 pandemic is equivalent to simultaneously calculating the changes in lifetime income, wealth transfers and public debt caused by the economic shock and the demographic shock. ${ }^{3}$ Hence, lifetime consumption captures three effects caused by the COVID-19 pandemic:

3 The lifetime consumption at age $x$ for a generation born in year $t$, denoted by $C_{i}(x, t)$, is equal to

$$
\sum_{s=x}^{99+}\left(\prod_{z=x}^{s} \frac{p_{i}(z, t+s)}{1+r}\right) c_{i}(s, t+s),
$$


(i) the decline in labour income, (ii) the changes in public and private transfers, and (iii) the increase in the mortality rate.

Figure 5 shows the impact of the COVID-19 pandemic on the remaining lifetime consumption relative to the average labour income for three age groups (i.e. 0-24, 25-64 and 65+). The results presented in Figure 5 are robust to changes in the underlying interest rate, which is assumed to be $2.5 \%$ (see the sensitivity analysis in Section S4 in the Supplementary Material). This is because individuals react to changes in prices in the OLG-NTA model, and the results are relative to labour income. For each country and age group, Figure 5 contains two bars that reflect the degree of government support to households. The red bars in Figure 5 show that without government support, the negative impact of the COVID-19 pandemic on lifetime consumption is larger for the 0-24 and 25-64 age groups than for the 65+ age group. Among the 12 NTA countries analysed, the 0-24 and 25-64 age groups are the worst hit in Italy, Austria and Slovenia; while the 65+ age group is the worst hit in Brazil, Hungary and Slovenia. These different effects across countries and age groups reflect the cross-country variation in the decrease in economic activity; the fraction of people infected in 2020; and the generosity of the public transfer system, which is well captured by the NTA profiles.

We start the analysis by focusing on the working age group. We then look at the $0-24$ age group, followed by the $65+$ age group. The results of the OLG-NTA model indicate that the decline in the remaining lifetime consumption for the 20 64 age group is driven by the fall in labour income and the negative impact of the COVID-19 pandemic on the survival probability. For the 0-24 age group, the decline is explained by the reduction in the transfers they receive from their parents (private transfers) and the increase in future taxes needed to pay for the additional debt generated during the crisis (see Figure 4). The decline in lifetime consumption for the $65+$ age group is caused by the loss of pension benefits and the increase in the mortality rate. When we compare the labour income losses to the decrease in lifetime consumption, we find that a $1 \%$ decline in labour income leads to an average decline in lifetime consumption of $0.73 \%$ for the $0-24$ age group, of $0.94 \%$ for the $25-64$ age group and of $0.32 \%$ for the $65+$ age group.

The turquoise bars in Figure 5 show that when the government fully compensates workers in the 25-64 age group for their labour income losses, the negative impact of the pandemic is more evenly distributed across all age groups. Indeed, when we compare the turquoise bars to the red bars we see that the negative impact of the pandemic on lifetime consumption is reduced on average by $56 \%$ for the $0-24$ age group, and by $52 \%$ for the 25-64 age group. Hence, despite the future increase in taxes caused by the government support (see Figure 4), people in the 0-24 age group

where $r$ is the market interest rate, $p_{i}(x, t)$ is the conditional probability of surviving to age $x$ in year $t$ and $c_{i}(x, t)$ is the total consumption (public and private) at age $x$ in year $t$. We define the difference in lifetime consumption at age $x$ for a generation born in year $t$ as $\Delta C(x, t)=C_{1}(x, t)-C_{0}(x . t)$. Subscript $i$ denotes whether the NTA-based model results are pre COVID-19 $(i=0)$ or post COVID-19 $(i=1)$. 


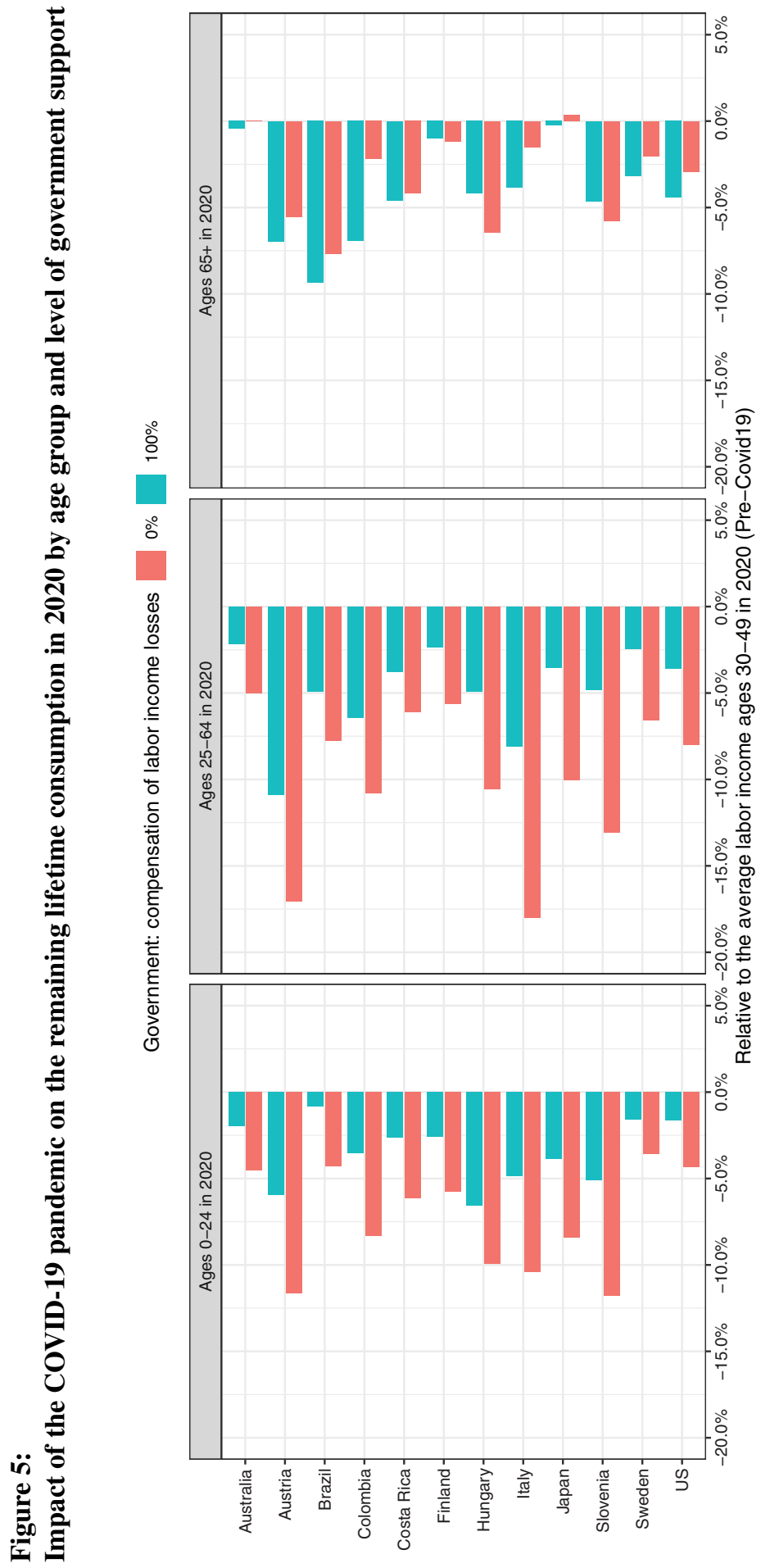


benefit the most from this policy, because they receive more transfers from the 2564 age group. This result should be interpreted with caution, given that the positive effect of this policy on the 0-24 age group may be lower if the debt-to-GDP ratio is reduced more slowly than $10 \%$ per year, as this scenario implies that younger generations will have to pay more taxes when they enter the labour market. If we compare the labour income losses to the fall in lifetime consumption, we find that if the government fully compensates households for their labour income losses, a $1 \%$ decline in labour income leads to an average decline in lifetime consumption of $0.24 \%$ for the $0-24$ age group, of $0.46 \%$ for the $25-64$ age group and of $0.40 \%$ for the $65+$ age group.

It is also important to note that when the government fully compensates workers for their labour income losses, not all age groups benefit similarly in all countries. For instance, under this scenario, the 0-24 age group is the worst hit in Hungary, Austria and Slovenia; the 25-64 age group is the worst hit in Austria, Italy and Colombia; while the 65+ age group suffers the greatest losses in Brazil, Colombia and Austria. The differences in the ranking of countries with respect to the level of government support stem from the different transfer systems implemented in each country.

\subsection{Impact on public and private transfers}

To understand how the transfer system in each country shapes the impact of the COVID-19 pandemic, Figure 6 shows the impact of the crisis on lifetime transfers in 2020 by age group and level of government support. Like in Figure 5, the results are robust to changes in the interest rate (see the sensitivity analysis in Section S4 in the Supplementary Material). Figure 6 is divided into three panels. The top panel shows total lifetime transfers (i.e. the sum of public and private lifetime transfers), the middle panel A displays public lifetime transfers and the bottom panel B shows private lifetime transfers. The main difference between Figure 6 and all previous figures is that not all age groups are negatively affected by the COVID-19 pandemic. Specifically, Figure 6 shows that the impact of the COVID-19 pandemic on lifetime transfers is negative for the 0-24 age group, is positive for the 25-64 age group and is mixed for the $65+$ age group.

A comparison of the turquoise bars and the red bars in the top panel of Figure 6 shows that the negative impact of the COVID-19 pandemic on the 0-24 age group is more pronounced without additional support from the government. For instance, a $1 \%$ decline in labour income leads to an average decrease in total lifetime transfers of $0.61 \%$ with no additional support from the government, and of $0.29 \%$ with additional support from the government. However, contrary to our intuition, we find that the positive effect of compensating workers for their labour income losses is due to the increase in private lifetime transfers, and not to the increase in public lifetime transfers (c.f. panels A and B). Panel B (red bar in the bottom of the figure) shows that without additional public transfers, the 25-64 age group transfers 
Figure 6:

Impact of the COVID-19 pandemic on the remaining lifetime transfers in 2020 by age group and level of government support

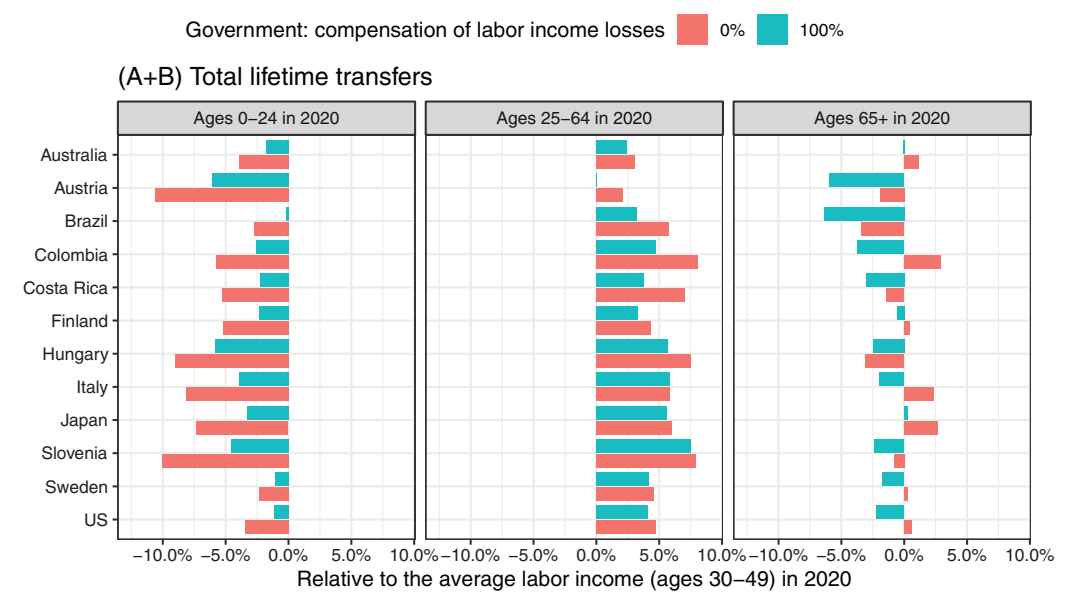

(A) Public lifetime transfers

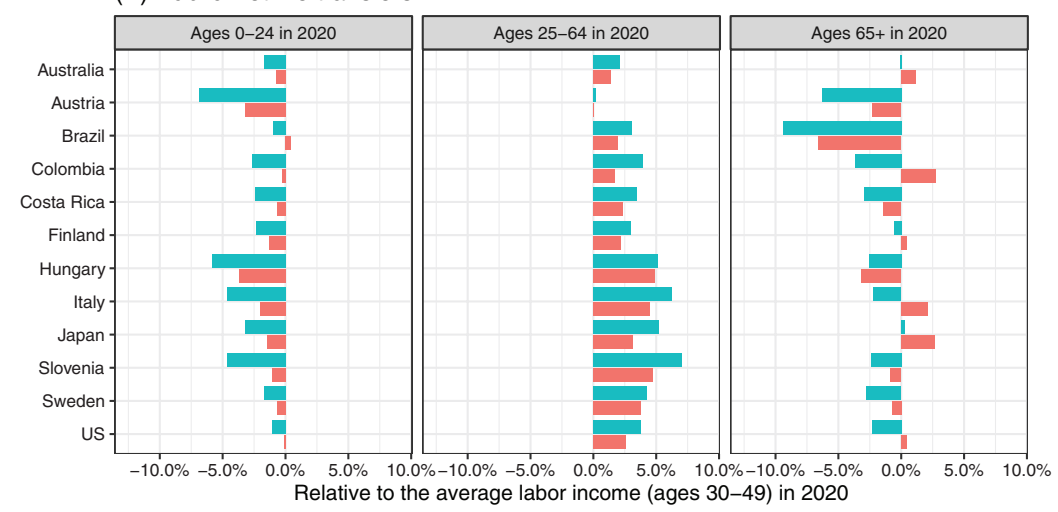

(B) Private lifetime transfers

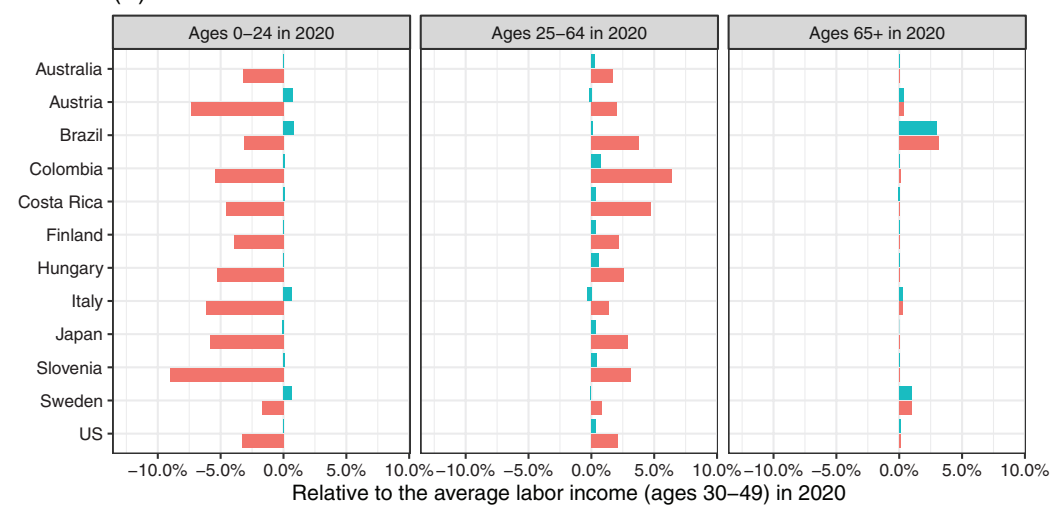

Source: Own calculations. 
fewer resources to the 0-24 age group (see panel A). Specifically, a 1\% decline in labour income reduces the private lifetime transfers of the $0-24$ age group by $0.48 \%$. In contrast, with $100 \%$ additional support from the government, a $1 \%$ decline in labour income increases the private lifetime transfers of the 0-24 age group by $0.03 \%$. Moreover, the red bars show that when there is no compensation for labour income losses, the impact of the COVID-19 pandemic on private lifetime transfers becomes positive for the 25-64 age group and negative for the 0-24 age group. By contrast, the turquoise bars show that if the government fully compensates workers for their labour income losses, the negative effect on the children's private lifetime transfers disappears. Therefore, we can conclude that the additional support of the government has an indirect positive effect on the private lifetime transfers received by the $0-24$ age group.

The direct impact of the additional government support on public lifetime transfers is shown in panel A (middle of the figure). The red bars in panel A illustrate how the economic crisis increases public lifetime transfers for the 25-64 age group. This effect is due to the lower taxes and social contributions paid by the 25-64 age group. The turquoise bars show that if the government compensates workers for their labour income losses during the crisis, the 25-64 age group receives more public transfers. The additional debt that this policy generates is paid back through future taxes by all age groups. As a consequence, the impact of the COVID-19 pandemic on public lifetime transfers for the $65+$ age group is mixed without the additional government support, and is negative when the government compensates workers for their labour income losses. The degree of the decline in public lifetime transfers for the 65+ age group is directly related to the amount of transfers received at older ages. Thus, for instance, given that Brazil has the most generous pension system among the 12 NTA countries analysed, the greatest decline in the public lifetime transfers can be observed in this country.

In sum, Figures 5 and 6 show that there is no one-size-fits-all policy that can be applied in all countries. Instead, when analysing the potential effects of policy approaches, we must account for each country's transfer system and demographic characteristics, which the NTA project and the OLG-NTA model allow us to do.

\section{Discussion}

Many economic models analysing the impact of the COVID-19 pandemic have assumed that all generations are equally affected by the crisis. These models do not include realistic demography, and some assume that the population can be modelled using a representative household. Moreover, they do not account for the negative impact that the COVID-19 pandemic is having on different age groups. In addition, these models fail to recognise that different generations are tightly linked to other generations through familial and public transfers. To complement these models, we have shown how to build and use an OLG-NTA model for assessing the economic impact of the COVID-19 crisis across generations. 
The OLG-NTA results show that a pandemic, like COVID-19, affects the financial situations of individuals aged 25 to 64 and their children more than those of other age groups. However, not all socioeconomic groups are equally affected. People in lower socioeconomic groups have a higher probability of losing their jobs and being infected with COVID-19. The simulation results suggest that providing workers with financial support will reduce household consumption declines, as well as poverty and inequality levels. In the less developed countries, remittances could also alleviate the decrease in income due to economic inactivity. However, given that the pandemic is affecting all countries, including the most developed countries, the decrease in remittances may be greater than the decline in labour income. Since we have estimated that the decrease in labour income across the 12 countries analysed is close to $10 \%$, the decline in remittances could exceed that figure.

This article has shown that an OLG-NTA model can be used for studying the impact of the COVID-19 pandemic on the generational economy, as well as for analysing the evolution of macroeconomic aggregates (i.e. total taxes, total public and private consumption, national income, debt, etc.). It is worth remembering, however, that a model is always a simplified representation of reality. All models are subject to limitations (assumptions), and knowing a model's limitations is always as informative as knowing its results. For instance, the current version of the OLGNTA model cannot be used to understand how a pandemic, like COVID-19, affects different population subgroups that differ by socioeconomic status. Existing OLG models that include three generations who differ by education and health status have shown that after a pandemic, the proportion of low socioeconomic groups may increase in the medium term (Boucekkine and Laffargue, 2010), which leads to an increase in inequality. To include these characteristics, it is necessary to have NTA profiles distinguished by socioeconomic status, many of which are still not publicly available, and to endogenise the education decision. The static and dynamic general equilibrium (GE) models that incorporate a social accounting matrix, such as those developed by the NTA teams in Bangladesh and Moldova, are, in principle, preferable for analysing the short-run impact of the COVID-19 pandemic on specific socioeconomic groups. However, these models are not suitable for studying the medium- and long-term effects of the COVID-19 crisis on the economy and the population.

The current version of the OLG-NTA model assumes that the COVID-19 pandemic will not have a permanent impact on public and private education. This possibility can be accounted for by using an alternative scenario from the WIC database or directly endogenising the educational decision. Another limitation of our model is that the decline in working hours is assumed to be proportionally distributed across all ages. In additional simulations that took into account that the labour income of young workers declined 50\% more than that of prime-age workers, the results did not significantly change (see the sensitivity analysis in Section S4 in the Supplementary Material). A fourth limitation is the lack of information on the decline in individual utility after the contraction caused by the COVID-19 pandemic. Yet another limitation is the modelling of the various waves of the virus. To include 
a second or a third wave of the virus in the model, we would need to introduce a trade-off between lockdowns and the probability of the return of the virus in a subsequent wave. These options can be considered as potential extensions of the model.

Some assumptions have been introduced for the sake of computational simplicity. For instance, the OLG-NTA model assumes an open economy with a fixed interest rate. A sensitivity analysis of the model to different interest rates showed that the results were robust to changes in the underlying interest rate (see Section S4 in the Supplementary Material). Although most countries operate with open capital markets, studying a closed economy could be interesting for understanding the total impact of changes in the population age structure on the economy through changes in the interest rate. Second, the model contains one sector only, and does not include trade (i.e. exports and imports). A two-sectors model in which the workers of one sector provide necessary goods and services and the workers of the second sector can work from home could help us better understand the economic impact of COVID-19 crisis. However, given the available NTA data, creating such a model is not yet feasible. Third, the households in our analysis are only comprised of parents (household heads) and their dependent children. While this household structure clearly reflects conditions in modern western societies, it might not fully represent the household composition of less developed countries, Asian countries and African countries. However, it is also true that most OLG models do not properly account for the changes in household structure over the lifecycle, which is an advantage of our OLG-NTA model. Fourth, the model is unisex. A two-sexes model could use all of the available NTA and NTTA data. However, a dynamic two-sexes OLG model is extremely complex, since the number of potential household heads varies stochastically over time. To implement this type of model, more stringent assumptions should be introduced.

Despite the major limitations of the OLG-NTA model presented here, it has a number of advantages, including that it is simple, and can be easily adapted to other ideas and extensions. Moreover, since the model is mainly data driven, the modeller can study many alternative policies by building alternative scenarios for countries in which all of the standard NTA profiles have been constructed.

\section{Supplementary material}

Available online at https://doi.org/10.1553/populationyearbook2022.res1.2

Supplementary file 1. List of abbreviations (S1), estimated GDP losses due to Covid-19 (S2), additional figures (S3), and sensitivity analysis (S4).

Supplementary file 2. Summary of publicly available NTA country profiles (S5). 


\section{Acknowledgements}

I acknowledge the financial support provided by UNFPA, and the helpful comments of two anonymous reviewers, of Anne Goujon (editor) and of many NTA members and colleagues, in building this model. In particular, I appreciate the comments and suggestions received from Gretchen Donehower, Michael Herrmann, Michael Kuhn, Ronald Lee, Sang-Hyop Lee, Andrew Mason, Marcel Merette, Tim Miller and Alexia Prskawetz. I am also grateful for the excellent discussions and feedback from participants at the session on generational perspectives on economic crisis at the 13th Global NTA Meeting, and to Latif Dramani, Bazlul Khondker, Olanrewaju Olaniyan and Valeriu Prohnitchi.

\section{ORCID}

Miguel Sánchez-Romero (i) https://orcid.org/0000-0002-5999-6522

\section{References}

Aassve, A., Cavalli, N., Mencarini, L., Plach, S., and Bacci, M. L. (2020). The COVID-19 pandemic and human fertility. Science, 369(6502), 370-371. https://doi.org/10.1126/ science.abc9520

Arthur, W. B., and McNicoll, G. (1978). Samuelson, population and intergenerational transfers. International Economic Review, 19(1), 241-246. https://doi.org/10.2307/ 2526407

Ben-Porath, Y. (1967). The production of human capital and the life cycle of earnings. The Journal of Political Economy, 75(4), 352-365.

Bloom, D. E., Kuhn, M., and Prettner, K. (2020). Modern infectious diseases: Macroeconomic impacts and policy responses (NBER Working Paper No. 27757). National Bureau of Economic Research, Cambridge, MA. https://doi.org/10.3386/w27757

Bommier, A., and Lee, R. D. (2003). Overlapping generations models with realistic demography. Journal Population Economics, 16(1), 135-160. https://doi.org/10.1007/ s001480100102

Boucekkine, R., and Laffargue, J. P. (2010). On the distributional consequences of epidemics. Journal of Economic Dynamics and Control, 34(2), 231-245. https://doi.org/10.1016/j. jedc.2009.09.003

Braun, R. A., Ikeda, D., and Joines, D. H. (2009). The saving rate in Japan: Why it has fallen and why it will remain low. International Economic Review, 50(1), 291-321. https://doi.org/10.1111/j.1468-2354.2008.00531.x

Brodeur, A., Gray, D., Islam, A., and Bhuiyan, S. (2021). A literature review of the economics of COVID-19. Journal of Economic Surveys, 35, 1007-1044. https://doi.org/10.1111/joes. 12423 
Brotherhood, L., Kircher, P., Santos, C., and Tertilt, M. (2020). An economic model of the COVID-19 epidemic: The importance of testing and age-specific policies (CESifo Working Paper No. 8316). Center of Economic Studies, Munich. https://www.cesifo.org/ DocDL/cesifo1_wp8316.pdf

Eichenbaum, M. S., Rebelo, S., and Trabandt, M. (2020). The macroeconomics of epidemics (NBER Working Paper No. 26882). National Bureau of Economic Research, Cambridge, MA. https://doi.org/10.3386/w26882

Glover, A., Heathcote, J., Krueger, D., and Ríos-Rull, J. V. (2020). Health versus wealth: On the distributional effects of controlling a pandemic (NBER Working Paper No. 27046). National Bureau of Economic Research, Cambridge, MA. https://doi.org/10.3386/w27046

Krueger, D., Uhlig, H., and Xie, T. (2020). Macroeconomic dynamics and reallocation in an epidemic: Evaluating the "Swedish solution” (NBER Working Paper No. 27047). National Bureau of Economic Research, Cambridge, MA. https://doi.org/10.3386/w27047.

Lee, R. D. (1994). Age structure, intergenerational transfer, and wealth: A new approach, with applications to the United States. The Journal of Human Resources, 29(4), 1027-1063. https://doi.org/10.2307/146133

Lee, R. D., and Mason, A. (eds.). (2011). Population aging and the generational economy: A global perspective. Edward Elgar Publishing. https://doi.org/10.4337/9780857930583

Lee, R. D., Mason, A., and Miller, T. (2000). Life cycle saving and the demographic transition: The case of Taiwan. Population and Development Review, 26, Supplement: Population and Economic Change in East Asia, 194-219.

Lee, S. H., and Ogawa, N. (2011). Labor income over the lifecycle. In R. D. Lee and A. Mason (Eds.), Population aging and the generational economy (pp. 109-135). Edward Elgar Publishing.

Lopez-Leon, S., Wegman-Ostrosky, T., Perelman, C., Sepulveda, R., Rebolledo, P. A., Cuapio, A., and Villapol, S. (2021). More than 50 long-term effects of COVID-19: A systematic review and meta-analysis. Scientific Reports, 11, Article 16144. https://doi.org/10.1038/ s41598-021-95565-8.

Marshall, M. (2020). The lasting misery of coronavirus long-haulers. Nature, 14 September 2020. https://doi.org/10.1038/d41586-020-02598-6

National Transfer Accounts Data (2019). Retrieved 2 November 2020, from http://www. ntaccounts.org

Preston, S., Heuveline, P., and Guillot, M. (2001). Demography: Measuring and modeling population processes. Blackwell Publishers.

Samuelson, P. A. (1958). An exact consumption-loan model of interest with or without the social contrivance of money. Journal of Political Economy, 66(6), 467-482. https: //doi.org/10.1086/258100

Sánchez-Romero, M., Abio, G., Patxot, C., and Souto, G. (2018a). Contribution of demography to economic growth. SERIEs, 9, 27-64. https://doi.org/10.1007/s13209017-0164-y

Sánchez-Romero, M., di Lego, V., Prskawetz, A., and Queiroz, B. L. (2021). An indirect method to monitor the fraction of people ever infected with COVID-19: An application to the United States. PLOS ONE, 16(1), e0245845. https://doi.org/10.1371/journal.pone. 0245845 
Sánchez-Romero, M., Lee, R. D., and Prskawetz, A. (2020). Redistributive effects of different pension systems when longevity varies by socioeconomic status. The Journal of the Economics of Ageing, 17, 100259. https://doi.org/10.1016/j.jeoa.2020.100259

Sánchez-Romero, M., Wrzaczek, S., Prskawetz, A., and Feichtinger, G. (2018b). Does demography change wealth inequality? In G. Feichtinger, R. Kovacevic, and G. Tragler (Eds.), Control Systems and Mathematical Methods in Economics. Lecture Notes in Economics and Mathematical Systems, Vol. 687, (pp. 349-375). Springer. https://doi.org/ 10.1007/978-3-319-75169-6_17

Tobin, J. (1967). Life cycle saving and balanced growth. In W. Fellner et al. (Eds.), Ten Economic Studies in the Tradition of Irving Fischer (pp. 231-256). Wiley.

Townsend, L., Dowds, J., O’Brien, K., Sheill, G., Dyer, A. H., O’Kelly, B.,..., Bannan, C. (2021). Persistent poor health after COVID-19 is not associated with respiratory complications or initial disease severity. Annals of the American Thoracic Society, 18(6), 997-1003. https://doi.org/10.1513/AnnalsATS.202009-1175OC

United Nations, Department of Economic and Social Affairs, Population Division (2019). World Population Prospects 2019, Online Edition. Rev. 1. Retrieved 3 October 2020, from https://population.un.org/wpp/Download/Standard/Population/

Willis, R. J. (1988). A theory of the equilibrium interest rate in an overlapping generations model: life cycles, institutions, and population growth. In R. D. Lee, W. B. Arthur, and G. Rodgers (Eds.), Economics of changing age distributions in developed countries (pp. 106-138). Oxford University Press.

Wilson, T. (2020). Model Migration Schedule fitting example. figshare. Software. https: //doi.org/10.6084/m9.figshare.12415475.v3

Wittgenstein Centre for Demography and Global Human Capital (2018). Wittgenstein Centre Data Explorer Version 2.0. Retrieved 21 October 2020, from http://www. wittgensteincentre.org/dataexplorer

Wyplosz, C. (2020). The Euro Area After COVID-19. Monetary Dialogue Papers, November 2020, European Parliament. https://www.europarl.europa.eu/ cmsdata/214969/01.WYPLOSZ_final.pdf

\section{Appendix}

\section{A Demography}

The OLG-NTA based model relies on two alternative populations: (i) one population, denoted by 0, that never experienced the COVID-19 pandemic (UN Pop Projections before COVID-19); and (ii) another population, denoted by 1, that experienced the COVID-19 pandemic from the year 2020 until the vaccine was introduced. The duration of the influence of the COVID-19 pandemic and the proportion of infected people can be chosen by the modeller. 


\section{A.1 Survival probabilities}

The COVID-19 pandemic is assumed to have a negative impact on the mortality rate of those infected, and, because $20 \%$ of the symptomatic people report permanent symptoms, we assume that $10 \%$ (symptomatic plus asymptomatic) of the infected individuals end up having long-term health effects that may increase their mortality risk (Marshall, 2020). Thus, we assume that the conditional probability of surviving to age $x$ after $t(=$ COVID-19) is

$$
p_{1}(x+n, t+n)=p_{0}(x+n, t+n)-\gamma(t+n) \delta_{C}(x+n) \quad \text { if } n=0
$$

and

$$
p_{1}(x+n, t+n)=p_{0}(x+n, t+n)-\gamma(t) \frac{\delta_{C}(x+n)}{10} \text { if } n>0
$$

where $p_{i}(x, t)$ is the conditional probability of surviving to age $x$ in year $t, \gamma(t)$ is the fraction of people infected in year $t$ and $\delta_{C}(x)$ is the infection fatality rate at age $x$.

The fertility, mortality, sex ratios at birth, net migration rates and population data are taken from the UN Population Division. The UN only reports population data by single years of age until 2020, while the NTA data are only available by single years of age. For the sake of consistency, we interpolate the UN data by five-year age groups to single years of age by using B-splines. Migration by single years of age is introduced using a net migration standardised age profile for Australia taken from Wilson (2020).

\section{A.2 Population projections}

Backward population projection. For our projection, we need individuals who are not affected by the COVID-19 pandemic over their whole lifetimes. Thus, we assume that before the year 1950, the mortality and fertility levels are the same as those observed in 1950 . We then project backwards by using the initial $L_{x}(1950)$ values, and we calculate the population growth rate (Lotka's r) of the Leslie matrix in 1950.

Forward population projection. We use a female-dominant population projection strategy based on Leslie $(L)$ matrices (Preston et al., 2001). We assume an open population, and that the Leslie matrix is filled with the UN's data and assumptions.

$$
\operatorname{Pop}(t+1)=L(t)(\operatorname{Pop}(t)+0.5 I(t))+0.5 I(t)
$$

where $L(t)$ is the Leslie matrix in year $t, \operatorname{Pop}(t)$ is a vector with the population size at each age in year $t$ and $I(t)$ is a vector with the total (net) migrants at each age in year $t$. 


\section{B Economy/National Transfer Accounts (NTA)}

The economic problem (household problem) is first solved for all generations using the population 0 (pre COVID-19). This exercise will give us the consumption path and the asset holdings for all generations at all ages. Second, using the population 1 (post COVID-19), the household problem is solved for all generations born after 2020. For those generations who are alive in 2020, the household problem should be solved from the age they reach in 2020, using as an initial condition the capital profile obtained with the model without the COVID-19 pandemic.

\section{B.1 Per capita profiles}

In constructing the OLG-NTA model, we distinguish three sets of profiles: (i) raw NTA profiles; (ii) exogenously constructed NTA profiles; and (iii) endogenously calculated NTA profiles.

\section{B.1.1 Raw NTA profiles}

All raw NTA profiles are standardised each year by the average labour income between ages 30-49. We use this measure of standardisation in order to reduce the importance of individuals' educational and retirement decisions in the simulation results. Thus, the per capita raw NTA profile of individuals with age $x$ at time $t$ is given by

$$
\text { NTA Profile }(x, t)=\frac{\underline{Y L}(t)}{\underline{Y L}(s)} N T A \operatorname{Profile}(x, s),
$$

where $Y L(t)$ is the average labour income between ages 30-49 in year $t$ and $s$ is the last year in which the NTA profile has been calculated. Table 1 shows the raw NTA profiles used in the OLG-NTA model.

\section{B.1.2 Exogenously constructed NTA profiles: Household problem}

In this category, we have four profiles: (i) labour income (YL); (ii) public transfers, health (TGH/CGH); (iii) social protection, unemployment; and (iv) inter-household transfers from retirees to adult children.

\section{Labour income (YL)}

The labour income profile of a cohort is assumed to be driven by three components: (i) the wage per efficient unit of labour per hour worked $w$; (ii) cohort and age-specific productivity, which depends on the experience and on the mean years of schooling $h(x, E d)$; and (iii) the number of hours worked $l$. The wage per efficient unit of labour rate per hour worked is solved in the firm subsection (See the Appendix). The cohort and age-specific productivity profile is given by a standard 
Mincerian equation

$$
h(x, E d)=\exp \left\{\rho(E d) E d+\beta_{0}(x-7-E d)-\beta_{1}(x-7-E d)^{2}\right\},
$$

where $\rho(E d)$ is the rate of return to $E d$ mean years of schooling, and $\left(\beta_{0}, \beta_{1}\right)$ account for the return of experience on the age-specific productivity of each cohort. Following a strategy similar to that in Sánchez-Romero et al. (2020), we model the rate of return to education with the following simplified Ben-Porath (1967) technology

$$
\rho(E d)=\frac{1}{\left(1-\gamma_{E}\right) E d} \log \left(1+\theta_{E}\left(1-\gamma_{E}\right) E d\right),
$$

in which we have assumed for the sake of simplicity no depreciation of human capital. The terms $\gamma_{E}$ and $\theta_{E}$ are, respectively, the returns to scale of education and the learning ability level. Thus, throughout the cohort and age-specific productivity profile, the cross-sectional labour income profiles reflect the heterogeneity across generations in the mean years of schooling. We follow the literature and assume that $\gamma_{E}=0.6$ and $\theta_{E}=0.20$, which yields an average return to finishing secondary education of $9.5 \%$. The mean years of schooling by birth cohort are taken from the WIC Human Capital Explorer database. We use this database because it provides the mean years spent in school, classified by sex and by five-year age groups from 1950 to 2100, which coincide in time with the data reported by the UN Population Division. Moreover, the data are available in all scenarios and at all geographical scales.

Given that countries have different labour market settings and institutions, which would imply that a complex labour supply model is needed for each country, we take from the AGENTA project the average number of hours worked (see the National Time Transfer Accounts tab). As a result, the average labour income received by individuals of age $x$ in year $t$ is given by

$$
Y L(x, t)=w(t) h(x, E d(t-x)) l(x) .
$$

This function should be able to replicate well the labour income profile for each country, especially when the average number of hours worked for the country is used. See Lee and Ogawa (2011) for a comparison of alternative labour income profiles across NTA countries.

\section{Public Transfers, Health, Inflows (TGHI)}

We assume that public transfers, health, inflows (TGHI) at age $x$ in year $t$ in a country vary with the average labour income between ages 30 and 49 in that country, which we denote by $\underline{Y L}(t)$, and with the probability of dying at the same age $x$ in year $t$ as follows:

$$
\operatorname{TGHI}(x, t)=\left(\frac{q(x, t)}{q(x, s)}\right)^{\gamma_{q}}(\underline{\underline{Y L}(t)})^{\gamma_{y}} \operatorname{TGHI}(x, s),
$$


where $q(x, t)$ is the probability of dying between $x$ and $x+1$ in year $t$ and $s$ is the year of the selected NTA profile. The terms $\gamma_{q}$ and $\gamma_{y}$ capture how sensitive the public health care expenditure is to changes in the probability of dying and labour income, respectively.

\section{Social protection (due to the COVID-19 pandemic)}

To incorporate policies that protect workers from labour income losses due to the lockdown measures, it is assumed that a fraction $\phi_{U}$ of the labour income lost is paid by the public sector

$$
U(x, t)=\phi_{U} \epsilon(t) Y L(x, t),
$$

where $\epsilon(t)$ is the percentage decrease in the number of working-hours in year $t$. This profile is added to the other cash public transfers.

Interhousehold transfers from retirees to adult children: NTA profiles show that recipients of public pensions use them to assist their adult children when public pensions are sufficiently high. To account for this fact, when benefits are higher than a fraction $\xi_{1}$ of the average labour income of a prime-age worker $Y L$, we assume that a fraction $\xi_{2}$ is transferred to the adult children. Thus, the interhousehold transfer, outflow of individuals of age $x$ in year $t$ is

$$
\operatorname{TFBO}(x, t)=\xi_{2} \max \left(0, T G S O A I_{0}(x, t)-\xi_{1} \underline{Y L}(t)\right)
$$

where $\xi_{1}$ sets the pension benefit threshold from which retirees start making transfers to their adult children, and $\xi_{2}$ is the fraction of the excess pension that is transferred to the adult children.

Following Sánchez-Romero et al. (2018b), we calculate the amount of transfers received by children at age $x$ in year $t$ using the following expression:

$$
\operatorname{TFBI}(x, t)=\sum_{s=x+12}^{\min (99+, x+52)} \psi_{t-x}(s, t) \zeta(s, t) \operatorname{TFBO}(s, t)
$$

where the first term $\psi_{t-x}(s, t)$ is the probability that an individual born in year $t-x$ has a living parent of age $s$ in year $t$; and the second term $\zeta(s, t)$ represents the fraction of TFBO that is received from a parent of age $s$ in year $t$, which is a function of the expected number of siblings.

Both $\operatorname{TFBO}(x, t)$ and $\operatorname{TFBI}(x, t)$ are added to TFB.

\section{B.1.3 Endogenously constructed NTA profiles (Household problem)}

We implement a standard lifecycle problem for each birth cohort in which household heads optimally decide their consumption and the consumption of their children. The solution to this problem is used to construct the following profiles: (a) private consumption (other than health and education), (b) intra-household transfers and 
(c) the private asset-based reallocation. For the sake of notational simplicity, in this section, we remove the variables age and time, and represent the variables in the next period with a prime symbol (').

- Pre COVID-19: This will determine the consumption path of private goods and services (other than health and education) of the household $\left(c^{F}\right)$ and the assets held (a) over the lifecycle without the COVID-19 pandemic.

$$
\begin{aligned}
\max _{c} V\left(a_{0}\right) & =U\left(c_{0}{ }^{F}, \eta_{0}\right)+\frac{1}{1+\rho} p_{0}{ }^{\prime} V\left(a_{0}{ }^{\prime}\right) \\
\text { s.t. } a_{0}{ }^{\prime} & =R_{0} a_{0}+w h l-c_{0}{ }^{F}+\tau_{0}{ }^{F}+\tau_{0}^{G, i n-C a s h}-\tau_{0}^{G,-}
\end{aligned}
$$

- Post COVID-19: In this regime, both the economy and the population changes. Household heads solve the following economic problem:

$$
\begin{aligned}
\max _{c} V\left(a_{1}\right) & =U\left(c_{1}{ }^{F}, \eta_{1}\right)+\frac{1}{1+\rho} p_{1}{ }^{\prime} V\left(a_{1}{ }^{\prime}\right) \\
\text { s.t. } a_{1}{ }^{\prime} & =R_{1} a_{1}+w h l(1-\epsilon)-(1+\theta) c_{1}{ }^{F}+\Theta+\tau_{1}{ }^{F}+\tau_{1}^{G, \text { in-Cash }}-\tau_{1}^{G,-}
\end{aligned}
$$

where $\rho$ is the subjective discount factor; $R_{i}=(1+r) / p_{i}$ is the compound interest rate that is gained by individuals in case of surviving; $a$ are the assets held, which can be comprised of investments in firms, national debt and internationally traded bonds; and $\epsilon$ denotes the decline in labour income caused by the COVID-19 pandemic. The term $\theta$ is the tax rate on consumption, which is a proxy for containment measures aimed at encouraging social distancing (Eichenbaum et al., 2020); and $\Theta=\theta c^{F}$ are the lump sum transfers from the government. $\tau^{F}$ denotes the sum of the private consumption of health and education and the interhousehold transfers, $\tau^{G \text {,in-Cash }}$ denotes all of the public cash transfers received and $\tau^{G,-}$ denotes all of the taxes and social contributions paid. The following NTA profiles are included in each variable:

- $\tau_{i}^{F}=\left(\eta_{E i}+C F E_{i}\right)+\left(\eta_{H i}+C F H_{i}\right)+T F B_{i}$

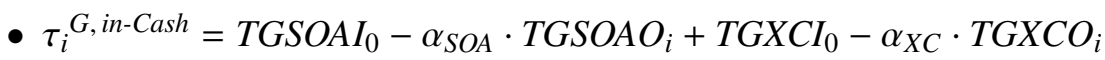

- $\tau_{i}^{G,-}=T G E O_{i}+T G H O_{i}+T G X O_{i}$

where $\eta_{X i}$ is the cost of children on the good/service $X$.

\section{Solution}

Assuming, similar to Lee et al. (2000) Braun et al. (2009) and Sánchez-Romero et al. (2018a), that $U\left(c^{F}, \eta_{i}\right)=\left(1+\eta_{i}\right) \log \left(\frac{c^{F}}{1+\eta_{i}}-C\right)$, where $C$ is the minimum consumption level, the household problem can be recursively solved using the following system of dynamic equations

$$
\begin{aligned}
& a_{i}{ }^{\prime}=R_{i} a_{i}+w h l(1-\epsilon)-\left(1+\eta_{i}\right)\left(C+\frac{1}{1+\theta} \frac{R_{i}}{\lambda_{i}}\right)+\tau_{i}^{F}+\tau_{i}^{G, i n-\text { Cash }}-\tau_{i}^{G,-}, \\
& \lambda_{i}{ }^{\prime}=\lambda_{i}(1+\rho) /\left(R_{i} p_{i}{ }^{\prime}\right),
\end{aligned}
$$


where the private consumption of the household is $\left(1+\eta_{i}\right)\left(C+\frac{1}{1+\theta} \frac{R_{i}}{\lambda_{i}}\right)$ and the private consumption of the household head is $C+\frac{1}{1+\theta} \frac{R_{i}}{\lambda_{i}}$. Thus, conditional on an initial value for the assets held $a$, the household problem is solved when the initial guess of $\lambda$ indicates that the assets held at the maximum age is zero. The initial value of $\lambda$ can be obtained using a root-finding algorithm (e.g. Bisection method, Regular farsi, Newton-Raphson method, etc.).

\section{B.1.4 Interhousehold transfers}

The number of children: The average number of children below age $A$ per adult is given by the following formula (see Sánchez-Romero et al., 2018b):

$$
\eta_{X}(x, t)=\sum_{s=12}^{x} \frac{L(s, t-s) F_{x}(s, t-s)}{L(x, t)} \frac{L(x-s, t)}{1+S R B(t-s)} X(x-s) 1_{\{x-s \leq A\}},
$$

where $L(x, t)$ is the person-years lived at age $x$ in year $t, S R B(t)$ is the sex ratio at birth in year $t, X$ denotes the consumption profile and $A$ is the age of leaving the parental home.

Fraction of interhousehold transfers received: If parents leave one monetary unit that is equally split between all surviving offspring, Sánchez-Romero et al. (2018b) show in Eq. (47) that this fraction is given by the following expression:

$$
\zeta(s, t)=\frac{1-e^{-\eta(s, t)}}{\eta(s, t)}
$$

where $\eta(s, t)$ is the total number of offspring from an individual of age $s$ in year $t$, which can be calculated by removing the last two components in $\eta_{X}(s, t)$.

Allocation child consumption: The consumption of a child of age $x$ in year $t$ is proportional to the consumption of her/his parents. Since we do not know with certainty the age of the parent, we calculate the probable age of the parent by using the first row of the Leslie matrix when the individual was born. Thus, we have that the consumption of a child of age $x \in(x, A)$ in year $t$ is given by

$$
c^{F}(x, t)=\theta(x) \sum_{s=x+12}^{x+52} \psi_{t-x}(s, t) c^{F}(s, t)
$$

where $\psi_{t-x}(s, t)$ is the probability that an individual born in year $t-x$ has a living parent of age $s$ in year $t$

$$
\psi_{t-x}(s, t)=\frac{F_{p}(s-x, t-x) \operatorname{Pop}(s, t)}{\sum_{s=x+12}^{x+52} F_{p}(s-x, t-x) \operatorname{Pop}(s-x, t-x)}
$$

$F_{p}(s-x, t-x)$ is the probability that a child was born of a mother of age $s-x$ in year $t-x$, which is obtained by multiplying the first row of the Leslie matrix by the population size and dividing by the total number of births in year $t-x$. 


\section{B.2 Aggregate profiles}

The macro dimension of the OLG-NTA model is described by aggregate profiles that are obtained by multiplying the per capita profiles by the population size at each age. The sum across ages of the aggregate profiles gives the macro totals from National Accounts. This is an important step, because the aggregate totals affect the inflows and/or the outflows of public transfers due to the constraints imposed by public budgets. To simplify the calculation, we assume that governments run a balanced budget in all years except for those affected by the COVID-19 pandemic; that is, all public inflows are equal to all public outflows.

To adjust all public NTA profiles forwards and backwards in time, we introduce a temporal adjustment factor, which is denoted by $\alpha_{j}$ for $j \in\{S O A, X C, H, E, X\}$. In particular, we assume that in-cash public transfer outflows and health care public transfer outflows (i.e. social contributions and taxes) are adjusted to finance all the in-cash public transfer inflows (i.e. pensions, social benefits, unemployment, etc.) and health care public transfer inflows (TGHI). Since in-cash transfers and health care spending are mostly received by elderly people, this adjustment implies that social contributions and taxes that pay for social benefits and health care will increase in the future, and were lower in the past. In contrast, since in-kind public transfers inflows for education and other in-kind benefits are mostly received during childhood, we adjust the level of in-kind public transfer outflows (i.e. taxes). Therefore, in-kind public transfer outflows will either decrease or remain the same relative to labour income in the future, and were higher in the past. Thus, we have

Public Transfers, in-cash

- Pensions:

$$
\sum_{x=0}^{99+} \operatorname{TGSOAI}_{0}(x, t) \operatorname{Pop}_{0}(x, t)=\alpha_{S O A}(t) \sum_{x=0}^{99+} \operatorname{TGSOAO}_{0}(x, t) \operatorname{Pop}_{0}(x, t)
$$

- Other than pensions:

$$
\sum_{x=0}^{99+} T G X C I_{0}(x, t) \operatorname{Pop}_{0}(x, t)=\alpha_{X C}(t) \sum_{x=0}^{99+} T G S X C O_{0}(x, t) \operatorname{Pop}_{0}(x, t)
$$

Public Transfers, in-kind

- Health:

$$
\sum_{x=0}^{99+} \operatorname{TGHCI}_{0}(x, t) \operatorname{Pop}_{0}(x, t)=\alpha_{H}(t) \sum_{x=0}^{99+} T G H O_{0}(x, t) \operatorname{Pop}_{0}(x, t)
$$

- Education:

$$
\alpha_{E}(t) \sum_{x=0}^{99+} T G E I_{0}(x, t) \operatorname{Pop}_{0}(x, t)=\sum_{x=0}^{99+} T G E O_{0}(x, t) \operatorname{Pop}_{0}(x, t)
$$


- Other in-kind:

$$
\alpha_{X}(t) \sum_{x=0}^{99+} T G X I_{0}(x, t) \operatorname{Pop}_{0}(x, t)=\sum_{x=0}^{99+} T G X O_{0}(x, t) \operatorname{Pop}_{0}(x, t)
$$

where $\operatorname{Pop}_{0}(x, t)$ is the population size of age $x$ in year $t$.

To isolate the economic impact of the COVID-19 pandemic, the balanced budget assumption is relaxed from 2020 until the vaccine for COVID-19 is introduced. We use two alternative populations: one population that is based on the UN Population Division data, labelled with subscript 0; and a second population that is affected by the COVID-19 pandemic, which is labelled with subscript 1 . Given that most countries have chosen to implement expansionary fiscal policies to reduce the economic burden of the COVID-19 pandemic, the NTA-based model assumes that public transfer inflows remain unchanged during the period in which the COVID19 pandemic is affecting the population, and that only the public transfer outflows are adjusted because of labour income losses. Consequently, governments will run deficits and their debt levels will increase. We further assume that after the vaccine is introduced, additional taxes are collected in a way that reduces the debt at a proportional rate. To allow the NTA-based model to have a temporary imbalance in the public budget, we use the same temporal adjustment factors $\alpha_{j}(t)$ for $j \in\{S O A, X C, E, X\}$ calculated without the COVID-19 pandemic.

\section{B.3 Firms}

We assume there is a single good, which can be consumed or saved, and which is produced with a combination of capital and labour, using a Cobb-Douglas production function. Both the labour market and the capital market are assumed to be competitive. Under an open economy with a fixed (real) interest rate $r$ and depreciation of capital $\delta_{K}$, the wage rate in year $t$ is given by

$$
w(t)=\Gamma(t)\left(\frac{\alpha_{Y}}{r+\delta_{K}}\right)^{\frac{\alpha_{Y}}{1-\alpha_{Y}}}
$$

where $\Gamma(t)$ is the level of technology, which is assumed to increase at a rate $g_{\Gamma}$ annually; $\Gamma(t+1)=\left(1+g_{\Gamma}\right) \Gamma(t)$, and $\alpha_{Y}$ is the capital share. The total output is

$$
Y(t)=\frac{1}{1-\alpha_{Y}} \sum_{x=0}^{\Omega} Y L(x, t) \operatorname{Pop}(x, t),
$$

where the labour income at age $x$ in year $t, Y L(x, t)$, is given by $w(t) h(x, t) l(x)$. 
Figure B.1:

In sample performance of the model fitting the NTA profiles of Austria in the year 2010

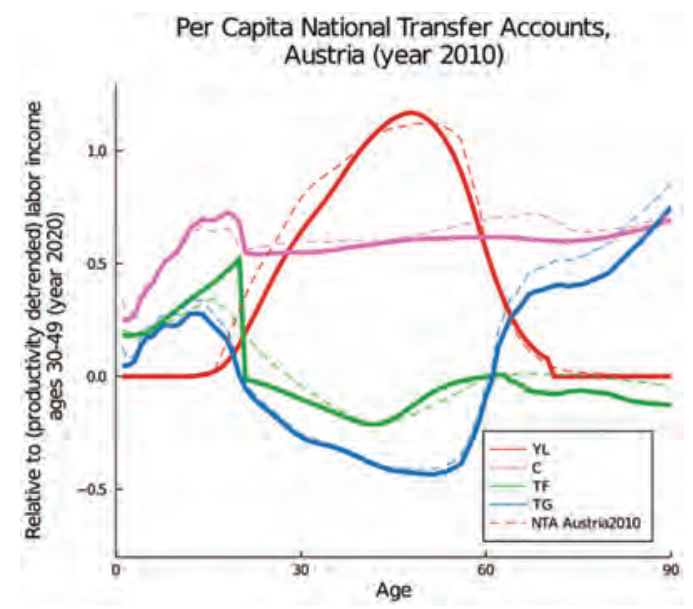

Notes: The dashed lines depict the NTA data, while the solid lines depict the per capita age profiles obtained with the OLG-NTA model.

\section{B.4 Government}

We assume that all public transfer inflows are financed by all transfer outflows in the scenario with no COVID-19 pandemic. However, in the scenario with the COVID19 pandemic, each country has an imbalance in its public budget

$$
B(t+1)=(1+r) B(t)+\tau^{G,+}(t)-\tau^{G,-}(t)
$$

which is financed through additional taxes, such that the evolution of debt satisfies the following rule:

$$
B(t+1)=B(t)+\phi_{B}(b Y(t)-B(t)) .
$$

The term $\phi_{B}$ is the rate of convergence of public debt to the targeted debt-to-output ratio $b$.

\section{B.5 Exogenous parameters}

Figure B.1 shows the fit of the model to the per capita national transfer accounts for Austria in the year 2010 using the exogenous parameters provided in Table B.1. 
Table B.1:

Exogenous parameters

\begin{tabular}{lcc}
\hline Parameters & Symbol & Value \\
\hline Productivity growth rate & $g_{\Gamma}$ & $1.5 \%$ \\
Return to experience & $\beta_{0}$ & 0.070 \\
& $\beta_{1}$ & 0.0009 \\
Subjective discount factor & $\rho$ & 0 \\
Capital share & $\alpha_{Y}$ & 0.33 \\
Depreciation of capital & $\alpha_{K}$ & 0.05 \\
(Real) interest rate & $r$ & $2.5 \%$ \\
Maximum age & $\Omega$ & $99+$ \\
Age at leaving home & $\mathrm{A}$ & 21 \\
Interhousehold transfers & $\xi_{1}$ & $50 \%$ \\
& $\xi_{2}$ & $50 \%$ \\
Health care elasticities & $\gamma_{q}$ & 0.20 \\
& $\gamma_{y}$ & 1.00 \\
\hline
\end{tabular}

Open Access This article is published under the terms of the Creative Commons Attribution 4.0 International License (https://creativecommons.org/licenses/by/4.0/) that allows the sharing, use and adaptation in any medium, provided that the user gives appropriate credit, provides a link to the license, and indicates if changes were made. 